Asian Journal of Pharmaceutical Research and Development

(An International Peer-Reviewed Journal of Pharmaceutical Research and Development) Open Access to Pharmaceutical and Medical Research

(C) 2013-18, publisher and licensee AJPRD, This is an Open Access article which permits unrestricted non-commercial use, provided the original work is properly cited

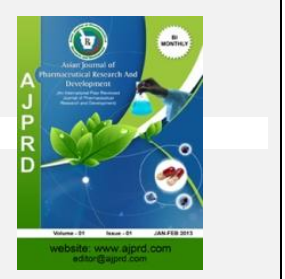

Open $\odot$ Access

Research Article

\title{
A VALIDATED REVERSED PHASE UHPLC METHOD FOR SIMULTANEOUS ESTIMATION OF ACECLOFENAC AND PARACETAMOL IN BULK AND PHARMACEUTICAL DOSAGE FORM
}

\section{Himakshi Baishya , Barnali Gogoi, Ripunjoy Bordoloi*, Parthajyoti Gogoi}

Regional Drugs Testing Laboratory (RDTL), Sixmile- 781022, Guwahati, India.

\begin{abstract}
The purpose of this present work is to develop and validate a simple, linear, accurate and precise reversed phase U-High Performance Liquid Chromatography method for the simultaneous estimation of Paracetamol and Aceclofenac in tablet dosage form (fixed dose combination formulation). For this, the analysis was carried out by High Performance Liquid Chromatography using U-HPLC System (Thermo-Dionex) equipped with an UV detector and stainless steel column $(25 \mathrm{~cm} \times 4.6 \mathrm{~mm} \times 5 \mu \mathrm{m})$ packed with octadecylsilane chemically bonded to porous silica column. The mobile phase contain buffer, adjusted to pH 7.5 with 1(M) sodium hydroxide and Acetonitrile in the ratio of $60: 40 \mathrm{v} / \mathrm{v}$ with a flow rate of $1.5 \mathrm{~mL} / \mathrm{min}$ and detection wavelength $272 \mathrm{~nm}$. The retention time of Paracetamol and Aceclofenac was found to be 1.698 and 2.548 respectively. The method was found to be linear in the concentration range of $10-100$ $\mu \mathrm{g} / \mathrm{mL}$ for Aceclofenac, $100-500 \mu \mathrm{g} / \mathrm{mL}$ for Paracetamol with correlation coefficient of 0.999 for both drugs respectively. The \%RSD of 0.660 and 0.689 for intra-day and 0.897 and 0.856 for inter-day precision, respectively for of Paracetamol and Aceclofenac suggest the precision of the method as all these values are less than 2\%. The method has shown good, consistent recoveries for Paracetamol (99.48\%) and Aceclofenac (99.42\%) which are close to 100\%. Thus, the current study showed that the developed reverse-phase liquid chromatography method is sensitive and selective for the estimation of Paracetamol and Aceclofenac in combined dosage form.
\end{abstract}

Keywords: UHPLC; Validation, Paracetamol, Aceclofenac

\section{Cite this article as:}

Bordoloi Ripunjoy, A Validated Reversed Phase UHPLC Method for Simultaneous Estimation of Aceclofenac and Paracetamol in Bulk and Pharmaceutical Dosage Form, Asian Journal of Pharmaceutical research and Development.2018;6 (2):1-5 DOI: http://dx.doi.org/10.22270/ajprd.v6.i2.365

*Address for Correspondence

Ripunjoy Bordoloi, Regional Drugs Testing Laboratory (RDTL), Sixmile- 781037, Guwahati, India

\section{INTRODUCTION}

$\mathrm{P}$ aracetamol and Aceclofenac are non-steroidal antiinflammatory drugs (NSAID) available as over the counter drug commonly used as analgesic and antipyretic in the management of fever and relief from mild to moderate pain. Paracetamol (acetaminophen) has weak anti-inflammatory effects since it has poor ability to inhibit cyclooxygenase (COX) in the presence of high concentration of peroxides, as are found at sites of inflammation. Chemically Paracetamol is 4- hydroxy acetanilide. Aceclofenac [[2-(2', 6'-dichlorophenyl) amino] phenyl acetoxyacetic acid] is a phenyl acetic acid derivative belongs to the group of non-steroidal antiinflammatory drug (NSAID) [1-3].

All conventional NSAIDs inhibit the conversion of arachidonic acid (AA) into prostaglandin $\mathrm{H}$ - PGH2. The stage is catalyzed by prostaglandin $\mathrm{H}$ synthase (PGHS), at present referred to as cyclooxygenase (COX) within which iso enzymes COX-1 (PGHS-1) and COX-2 (PGHS-2) occur.PGHS is a bifunctional enzyme and possesses two different enzymatic activities: cyclooxygenase and peroxidase (POX). The conversion of $\mathrm{AA} \rightarrow \mathrm{PGH} 2$ 
involves two reactions: cyclization of AA to unstable 15hydroxyperoxide (PGG2) with the involvement of a cyclooxygenase component and double oxidation in position 9 and 11; whereas the reduction of PGG2 molecule to its 15- hydroxy analogue, unstable structure of PGH2, takes place due to peroxidase activity of PGHS (POX). Prostaglandin $\mathrm{H} 2$ (PGH2) is a substrate for specific synthases, tissue-dependent isomerases catalyzing its further conversions into different endogenous regulators, namely: prostaglandins of the D (PGD2), E (PGE2), $\mathrm{F}$ (PGF2) series and prostacyclin (PGI2; prostacyclin is not a prostaglandin and a commonly used abbreviation is historically conditioned) and thromboxanes (TXA2 and TXB2). They all are characterized by different biological activity and many of them have antiinflammatory properties. Thus, the action of NSAIDs, which inhibits the stage of conversion $\mathrm{AA} \rightarrow \mathrm{PGH} 2$, and also the formation of the mentioned regulators, have some favorable (anti-inflammatory, analgesic and antipyretic) and side effects (associated with the inhibition of synthesis of particular regulators in different tissues). A precise mechanism of NSAID action together with therapeutic and side effects has been presented in the recently published large study by Nowak and Dzielska-Olczak and Nowak [45].

\section{Materials and Methods}

Paracetamol and Aceclofenac W/S were obtained as gift samples from Reddy's Laboratories, Hyderabad, India. Acetonitrile and Water (HPLC grade), sodium hydroxide and orthophosphoric acid were obtained from Merck Chemicals, Mumbai, India. Commercially available tablets (Acecloder TAB, Paracetamol 325 mg, Aceclofenac 100 $\mathrm{mg}$ ) were procured from local retail pharmacy..

\section{Chromatography instruments and conditions}

The Separation was performed by High Performance Liquid Chromatography using U-HPLC System (ThermoDionex) equipped with an UV detector and stainless steel column $(25 \mathrm{~cm} \times 4.6 \mathrm{~mm} \times 5 \mu \mathrm{m})$ packed with octadecylsilane chemically bonded to porous silica column.The mobile phase contain buffer, adjusted to $\mathrm{pH}$ 7.5 with $1(\mathrm{M})$ sodium hydroxide and Acetonitrile in the ratio of $60: 40 \mathrm{v} / \mathrm{v}$ with a flow rate of $1.5 \mathrm{~mL} / \mathrm{min}$ and detection wavelength $272 \mathrm{~nm}$. All the solutions were filtered through a 0.45 micron membrane filter paper and degassed before use.

\section{Preparation of standard solution}

Stock solutions were prepared by dissolving $10 \mathrm{mg}$ of Aceclofenac and Paracetamol in $10 \mathrm{ml}$ of the mobile phase to obtain a final concentration of $1000 \mathrm{mcg}$.

\section{Preparation of sample solution}

Twenty commercially available tablet containing Aceclofenac and Paracetamol (100mg and $325 \mathrm{mg}$ respectively) were weighed. The average weight was calculated and powdered. A quantity equivalent to $10 \mathrm{mg}$ of Aceclofenac was accurately weighed and transferred to a $100 \mathrm{ml}$ of volumetric flask. The sample was sonicated with the mobile phase. Further dilutions were made to get a concentration equivalent to the linearity range.

\section{Results and Discussion}

\section{Optimization of chromatographic conditions}

To develop a method for the analysis of the drugs, preliminary tests were performed in order to select adequate and optimum conditions. Parameters such as detection wavelength, ideal mobile phase and its combination, optimum $\mathrm{pH}$ and concentration of the standard solutions were studied. Mobile phase consist of buffer and Acetonitrile $(60: 40 \mathrm{v} / \mathrm{v})$. Flow rate was adjusted to $1.5 \mathrm{~mL} / \mathrm{min}$ and UV detection at $272 \mathrm{~nm}$ was selected for analysis. Retention time of Paracetamol and Aceclofenac were found to be 3.84 and $1.92 \mathrm{~min}$ respectively.

\section{Method validation}

\section{System suitability}

Six replicate of sample containing Paracetamol and Aceclofenac were given to evaluate equipment, analytical operations and samples suitability. Parameters calculated for system suitability were \%Relative Standard deviation (RSD), Retention time, Number of theoretical plates and Tailing factor.

\section{Linearity:}

Linearity for this analysis was established by least squares linear regression analysis. The calibration curves were found to be linear over the concentration range of 20-100 $\mathrm{mg} / \mathrm{ml}$ for Aceclofenac and $100-500 \mathrm{mg} / \mathrm{ml}$ for paracetamol. Further the peaks were plotted versus their respective concentrations and linear regression analysis was performed. The correlation coefficients were found to be 0.999 and 0.999 for Aceclofenac and Paracetamol respectively. (Table 1 ).

\section{Precision:}

The precision of the method was determined by intra-day and inter-day precision studies at $100 \%$ test concentration by measuring the sample three times on the same day at intervals of 1 hour and on three different days for intra and inter day studies respectively. Further standard deviation and relative standard deviation were calculated (Table 2).

\section{Accuracy}

The accuracy of the method was proven by recovery test. Known amounts of Paracetamol and Aceclofenac standard (50, 100 and $150 \%$ level were added to the already analyzed sample solutions and the analysis was carried out. The method has shown good, consistent recoveries for Paracetamol and Aceclofenac (99.48\% and 99.42\%)which are close to $100 \%$ as shown (Table 3 ). 
Robustness: The robustness of the method was checked by deliberately varying the mobile phase composition, wavelength and flow rate which shows that the small changes of the method parameters do not interfere the performance of the method. All the results obtained were in accordance with the results for original conditions. The $\%$ RSD value obtained for the assay in the changed condition was less than $2 \%$ which indicates the robustness of the proposed method. Solution stability:

The $\%$ RSD of the peak areas of the test samples were less than $1 \%$ for $24 \mathrm{hrs}$ which indicates that the sample was stable under proposed mobile phase condition within this period only.

\section{LOD and LOQ:}

Table 1: Linearity and Correlation coefficient

\begin{tabular}{|l|l|l|}
\hline Parameters & Paracetamol & Aceclofenac \\
\hline Regression equation & $\mathrm{y}=\mathbf{0 . 2 5 2 x}-\mathbf{0 . 0 3 4}$ & $\mathrm{y}=\mathbf{0 . 4 1 1 x}-\mathbf{0 . 1 4 7}$ \\
\hline Linearity $(\boldsymbol{\mu g} / \mathrm{ml})$ & $\mathbf{1 0 0 - 5 0 0}$ & $\mathbf{2 0 - 1 0 0}$ \\
\hline Correlation coefficient & $\mathbf{0 . 9 9 9}$ & $\mathbf{0 . 9 9 9}$ \\
\hline
\end{tabular}

Table 2: Precision studies

\begin{tabular}{|c|c|c|c|}
\hline Drug & Concentration $\boldsymbol{\mu g} / \mathbf{m l}$ & $\begin{array}{c}\text { Intraday Precision } \mathbf{n}=3 \\
\text { \%RSD }\end{array}$ & $\begin{array}{c}\text { Interday Precision n=3 } \\
\text { \% RSD }\end{array}$ \\
\hline Paracetamol & $100 \mu \mathrm{g} / \mathrm{ml}$ & 0.660 & 0.589 \\
\hline Aceclofenac & $100 \mu \mathrm{g} / \mathrm{ml}$ & 0.897 & 0.856 \\
\hline
\end{tabular}

Table 3: Accuracy

\begin{tabular}{|c|c|c|c|c|c|}
\hline \multirow{2}{*}{ Drug } & Amount taken & Amount added & $\begin{array}{c}\text { Amount } \\
\text { recovered }\end{array}$ & $\begin{array}{c}\text { \% Recovery \% } \\
\text { *RSD }\end{array}$ & $\begin{array}{c}\text { \% Recovery \% } \\
\text { *RSD }\end{array}$ \\
\hline \multirow{2}{*}{ Paracetamol } & & 162.5 & 161 & & \\
\cline { 2 - 6 } & 325 & 325 & 323.2 & 99.48 & 0.653 \\
\cline { 2 - 6 } & & 487.5 & 486 & & \\
\hline \multirow{2}{*}{ Aceclofenac } & & 50 & 48.6 & & 0.543 \\
\cline { 2 - 6 } & 100 & 100 & 98 & 99.42 & \\
\cline { 2 - 6 } & & 150 & 147.5 & & \\
\hline
\end{tabular}

Table 4: LOD and LOQ studies

\begin{tabular}{|c|c|c|}
\hline Validation parameters & Paracetamol & Aceclofenac \\
\hline LOD $\mu \mathrm{g} / \mathrm{ml}$ & 0.08 & 0.02 \\
\hline LOQ $\mu \mathrm{g} / \mathrm{ml}$ & 0.25 & 0.06 \\
\hline
\end{tabular}

Table 5: Analysis of Formulation

\begin{tabular}{|c|c|c|c|c|}
\hline Drug & $\begin{array}{c}\text { Labelled amount } \\
\text { (mg/tablet) }\end{array}$ & $\begin{array}{c}\text { Amount found } \\
\text { (mg/tablet) }\end{array}$ & \%Label claim & \%*RSD \\
\hline Paracetamol & 325 & 311.6 & 95.8 & 0.30 \\
\hline Aceclofenac & 100 & 96.5 & 96.5 & 0.28 \\
\hline
\end{tabular}




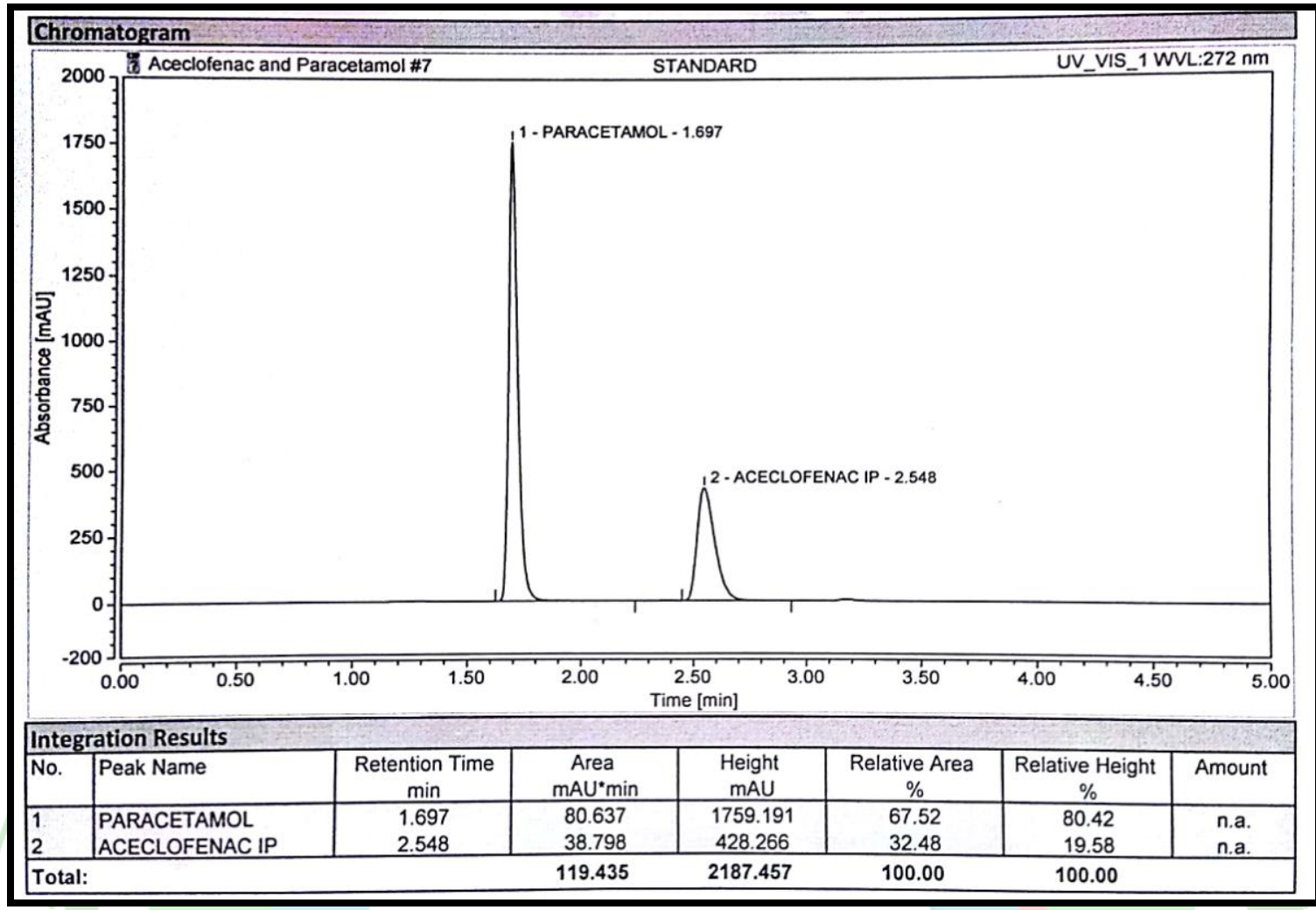

Fig 1: HPLC Chromatogram of Standard Paracetamol and Aceclofenac

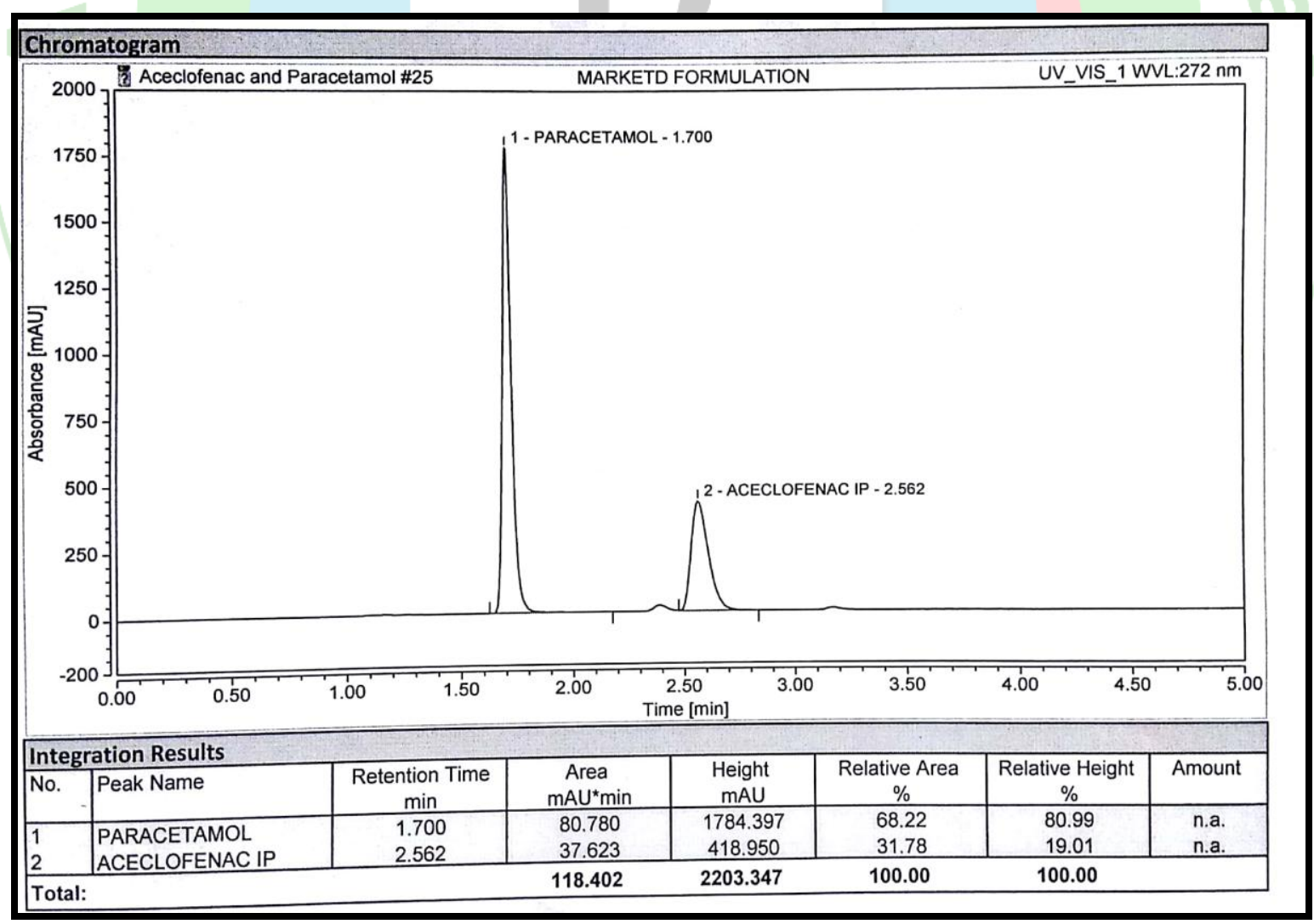

Fig 2: HPLC Chromatogram of Marketed Formulation 


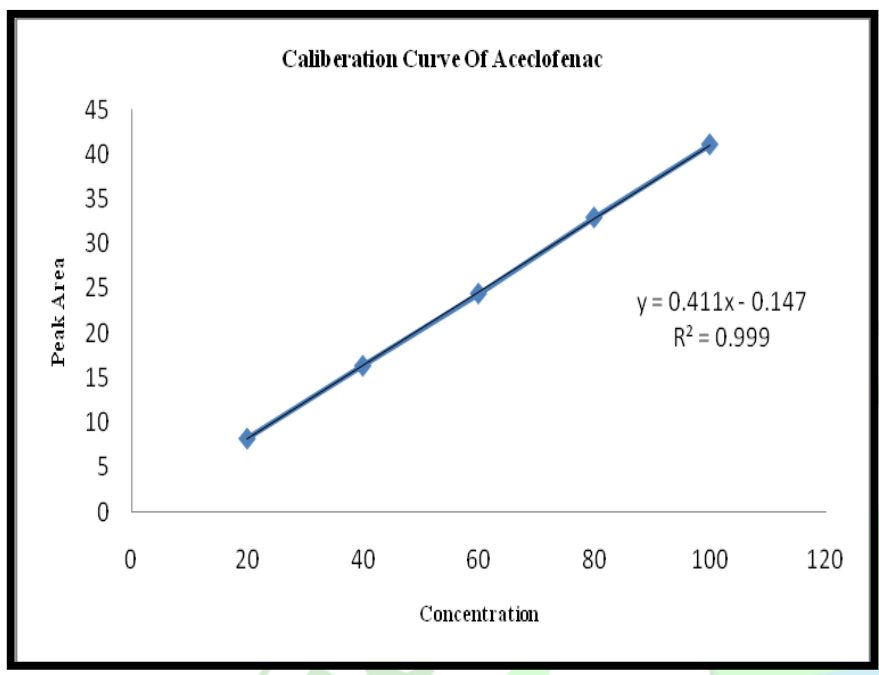

Fig 3: Caliberation Curve of Aceclofenac

\section{CONCLUSION}

The proposed U-HPLC method was found to be simple, precise, accurate and specific for the simultaneous estimation of Paracetamol and Aceclofenac .The newly developed method is simple and cost effective as it uses simple mobile phase without ion-pairing reagent which was previously unreported. The separation was done in 5 minutes only. The method was validated as per ICH guidelines. All other parameters such as specificity, linearity, precision, accuracy, robustness passes the criteria set forth by ICH guidelines. It is seen that was no

\section{REFERENCES}

1. Anderson BJ: Paracetamol (Acetaminophen): mechanisms of action. Paediatr Anaesth 2008; 18: 915-921.

2. Graham GG and Scott KF: Mechanism of action of Paracetamol. Am J Ther. 2005; 12:46-55.

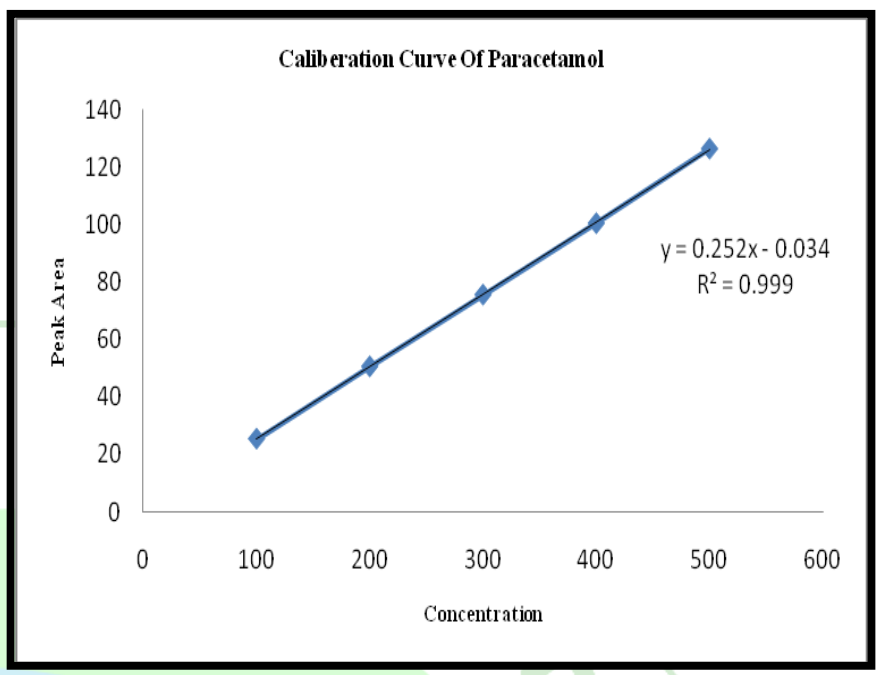

Fig 4: Caliberation Curve of Paracetamol

interference from any components of the formulation. Hence, this method can be easily used for routine quality control analysis of Paracetamol and Aceclofenac in pure and its combined dosage form.

\section{ACKNOWLEDGEMENT}

Sincere thanks to The Director of Regional Drugs Testing Laboratory (RDTL) Guwahati for supporting us in carrying out this research work.

3. Hinz B, Auge D, Rau T, Rietbrock S, Brune K, Werner U. Simultaneous determination of aceclofenac and three of its metabolites in human plasma by high-performance liquid chromatography. Biomed Chromatogr. 2003; 17(4):268-75.

4. Nowak J.Z.: Mil. Pharm. Med. 5, 33 (2012a).

5. Nowak J.Z.: Mag. Lek. Okul. 6, 57 (2012b) 